\title{
Using Analytic Rubric for Speaking Self-Assessment: EFL Students' Perceptions and Challenges
}

\author{
Thanh Xuan Phan, Hoang Yen Phuong \\ (Can Tho University, Vietnam)
}

\begin{abstract}
With the current Vietnamese teaching context, it can be challenging for teachers to assess students in large classes. Rubric, which makes assessment quick and efficient, is a promising way to solve this problem. Not only is rubric helpful to teachers, but students can be greatly benefited from it as well. The study was conducted from January to May, 2017 in Can Tho, to examine the two main aspects including (1) students' perceptions toward using Analytic Rubric for their self-assessment, and (2) some problems students encounter when they use the rubrics to assess themselves. The study involved 98 students from a high school in Vietnam. The research follows a descriptive approach with a thirty-four-item questionnaire of the five-point Likert scale to figure out the students' perceptions toward the use of Analytic rubric for their self-assessment. The data results from the questionnaires were treated via SPSS 20.0. The result showed that the students had positive perceptions toward the use of Analytic Rubric for their self-assessment. The study also revealed students' problems in using Analytic Rubric although the students did not have a clear perception towards the drawbacks of the rubric.
\end{abstract}

Keywords: analytic rubric, self-assessment, speaking, students' perceptions

\section{Introduction}

Assessment of speaking can be considered as an extremely difficult task for teachers, which involves a number of procedures. As for students, self-assessment in speaking used as a formative assessment tool, can promote learning, establish a goal-oriented activity, and lighten the work of the teachers. However, with the current teaching context in Vietnam, the oversize class makes it challenging for both students and teachers to assess their speaking performance in such limited time given for classroom activities. Rubric comes as a promising solution as it consists of set of scoring guidelines for evaluating students' work. To provide reliable and unbiased scoring, a rubric contains clear description for each criteria and scoring strategies. It can be assigned by numbers - the higher the number, the better the performance.

There was little literature about the use of Analytic Rubrics in Vietnam, especially for English as a foreign language (EFL) students in high school. This study, therefore, is an immediate necessity. As a high school teacher, the writer believes that the use of rubric can help students self-assess their performance if it can be used appropriately. With such a belief, the writer carried out the research on "Using analytic rubrics for speaking self-assessment: EFL students' perceptions and challenges."

The current study focuses on answering the three following research questions:

1. What are students' perceptions of using analytic rubric for their self-assessment in speaking performance?

2. What are students' perceptions toward the benefits of Analytic Rubric in the preparation and evaluation of their oral presentation?

3. What challenges do students encounter when they use Analytic Rubric?

\section{Rubrics}

\section{Literature Review}

In student assessment, a rubric is a set of scoring guidelines for evaluating students' work. Nitko [1] defined a scoring rubric as a coherent set of rules in order to assess the quality of a student's performance. It can be in a form of a rating scale or a checklist. A common definition of a rubric used by several researchers is the document presenting the expectation for a certain work by listing the criteria, describing the quality (from excellent to poor) [2]. To provide reliable and unbiased scoring, a rubric contains clear descriptions for each criterion and scoring strategy which involve the use of a scale for interpreting the judgment of a product or process. It can be assigned by numbers - the higher the number, the better the performance, as claimed by Wiggins [3].

There are two types of rubrics in common usage, namely holistic and analytic. Both are used to assess student products and performances [4]. A holistic rubric offers descriptions of different levels of overall performance. It gives a single score or rating for a product or performance. On the other hand, an analytic rubric breaks up a product or performance into discrete dimensions and judges each separately. Consequently, a separate score is provided for each trait and then combining each judgment to make a decision on the quality of the response [5]. The use of analytic rubric can make the scoring process slightly slower than the holistic one as 
evaluator has to assess several criteria individually. A holistic rubric is a suitable scoring tool when an overall impression is required, errors in some parts may be skipped as long as the overall quality is high, however, it does not provide students with the specific feedback about the strengths and weaknesses of their performance that is offered by analytic rubrics (Linn \& Gronlund, 2000). [5]. In this research, the writer would like to focus on the Analytic rubrics as it helps evaluate specific aspects of speaking/ presenting such as Non-verbal Skill, Verbal Skill, Contents and other criteria

\section{Students' Self-assessment}

According to Boud [6], all kinds of assessments conducted by teachers or learners have two functions. The first function is to develop knowledge and appreciate the appropriate standards and criteria. Judgment based on criteria is an emphasis in this definition. The second one is to make judgment about the work involved and to see the work is good or not. Nitko [1] defined assessment as a broad term, which means a process to obtain information used to make decision about students, curricula, program, and the educational policy.

Among other assessment methods, self-assessment is a novel method of assessing students and improving their learning. It is a key element in formative assessment because it involves students in reflecting their own work to the degree basing on stated goals or criteria; rather than depending too much on teacher's role. Students' self-assessment is done on drafts of works in progress to inform revision and improvement. Wiggins [7], who advocated the use of explicit criteria to enable students to self-assess, asserted that the development of self-assessment is inseparable from any assessment aimed at improving learning. It is the point that rubrics are being stated as a backbone of out-come-based assessment.

\section{Students' Perceptions toward Analytic Rubrics for self-assessment - Related studies}

Studies of students' responses to the use of rubrics show that graduate and undergraduate students value rubrics because these tools clarify the targets for their work, allow them to regulate their progress and make grades or marks meaningful and fair. The study in Bolton [8] asserted that 150 undergraduate and graduate business students are supported by rubrics in order to engage them in crucial processes, including recognizing the critical issues, reducing uncertainty and doing more meaningful work, determining the amount of effort needed for an assignment, evaluating their own product to get feedback on their weakness, pre-marking their grades before submission and improving their products after receiving feedback.

Similarly, Andrade and Du [9] also investigated 14 pre-service teachers' perceptions toward the use of rubrics. They claimed that rubrics helped them focus their efforts, produce better work, earn better grades and feel less anxious about assignments. They also emphasized that grading with rubrics is fair and transparent.

Powell [10] conducted a three-cycle action research inquiry. The researcher used rubrics to assess creative media projects. Qualitative analysis including questionnaires and interviews revealed that students would have better attitudes about fairness and satisfaction with grading when they are provided rubrics before the assignment with detail explanation.

Participants in the three studies mentioned above had been involved in courses in which rubrics were used as a part of formative, student-centered approach to assessment. Students raised positive responses when they took part in creating the rubrics or when rubrics were given at the beginning of the assignment. Schneider [11] compared the effect of using rubrics at different points in the assessment process. Fifty-five undergraduate education students were divided into 2 groups. The first group was given the rubric along with the assignment brief. The latter used rubric only after students received their marks. The researcher used a Likert-type survey and open-ended questions to collect students' reactions towards using rubrics and also their experiences. Schneider found that students in both groups would like to use the rubric again in the future. However, $88 \%$ of the students showed their preference on the rubric that was given prior the task, while only $10 \%$ found the rubric useful when it was provided only with a final grade. In brief, the researchers emphasize the instructional value of rubrics, not just a grading tool [12, 13, 14 and 15].

Although many studies have hypothesized the effects of Analytic rubric on language learners, little research related to this interest has been found in the area of Speaking Self-assessment. Thus, there is a need for exploration. The researchers intend to carry on this research to find out whether those beliefs are reliable or not.

\section{Participants}

\section{Research Methodology}

Ninety-eight students, including 69 females and 29 males in a high school in Vietnam were invited to participate in this study. The participants consisted of students studying the Pilot English program for Grade 10 and have already experienced the use of Analytic Rubric before. 
Using Analytic Rubric for Speaking Self-Assessment: EFL Students' Perceptions and Challenges..

\section{Research instruments}

The questionnaire included 34 items were employed to explore students' perceptions toward the use of Analytic Rubric for students' self-assessment in Speaking. The questionnaire was partly adapted from the survey Student Perceptions of Rubric Effectiveness - Revised 2014 by Haugnes and Russell[16]. The items of the questionnaire were grouped into 5 clusters.

\subsection{Pilot stage}

\section{Research procedure}

Firstly, 40 students were asked to participate in the pilot stage. The questionnaire had a Cronbach's alpha of 0.64. Therefore, this data collection instrument was quite acceptable according to Gliem [17]. Thanks to observing these students' reactions and answers for the first version of the questionnaire and their direct suggestions for the improvement of the questionnaire, the researcher added some suitable explanations and adjustments.

\subsection{Administering the questionnaire}

The researcher wrote the final version of the questionnaire in both Vietnamese and English versions. The researcher conducted the Vietnamese versions for the students to guarantee that the participants comprehend the items accurately.

\section{Findings}

1. Students' perceptions toward the use of analytic rubric for their speaking self-assessment

The findings of students' perceptions toward the use of rubric are presented in Table 1 below.

Table 1 Students' perceptions towards the use of rubric

\begin{tabular}{|c|c|c|c|}
\hline Item & Agree (\%) & Disagree $(\%)$ & No idea $(\%)$ \\
\hline $\begin{array}{l}\text { Item 18: I would like to know the criteria of the rubric before the } \\
\text { presentation day. }\end{array}$ & 80.7 & 3 & 16.3 \\
\hline $\begin{array}{l}\text { Item 8: It enables me to know the course expectations and self-assess my } \\
\text { skill and presentation performance. }\end{array}$ & 77.5 & 4.1 & 18.4 \\
\hline $\begin{array}{l}\text { Item 21: I would like to discuss with my friends and my teacher to create } \\
\text { the rubric. }\end{array}$ & 70.4 & 4.1 & 25.5 \\
\hline Item 10: It is easy to understand the rubrics. & 53.1 & 6.1 & 40.8 \\
\hline Item 3: I feel that it is easy for me to use rubric. & 45 & 8.1 & 46.9 \\
\hline Item 9: It is easy to use the rubrics & 40.8 & 10.2 & 49 \\
\hline Item 27 Rubrics don't make any difference in my study. & 30.4 & 40 & 29.6 \\
\hline Item 20: I like my teacher to assess me rather than using the rubrics & 22.5 & 25.5 & 52 \\
\hline $\begin{array}{l}\text { Item } 33 \text { Teacher must review the rubric with students before the } \\
\text { assignment. }\end{array}$ & 25.5 & 20.4 & 54.1 \\
\hline $\begin{array}{l}\text { Item 23: I just want my teacher to show me my weakness so I don't want } \\
\text { to use the rubrics }\end{array}$ & 16.3 & 58.2 & 25.5 \\
\hline
\end{tabular}

The three items that receive the most agreement from the student participants included Item 18, Item 8 and Item 21 of the questionnaire. More specifically, more than eighty percent of students claimed that they would like to know the criteria of the rubric before the presentation day. It may be because these criteria would help them prepare their oral presentation well. In addition, $77.5 \%$ of participants agreed that rubric helped them to know the course expectation as well as self-assess their skill and presentation performance. Furthermore, many students $(70.4 \%)$ showed that they would like to be involved in the process of creating the rubric used in the classrooms. The three items that received the agreement by almost half of the participants were Item 10 , Item 3 and Item 9. In particular, only $53.1 \%$ of participants perceived it easy to understand the rubrics. As a consequence, only $45 \%$ of the participants felt that it was easy for them to use the rubric and $40.8 \%$ agreed that it was easy to use the rubric. The two items that received the most disagreement from the participants were Item 23 and Item 27. With Item 23, 58\% of participants disagreed that they wanted their teacher to show them their weakness and did not want to use the rubrics. It can be inferred from this finding that students wanted the teacher to use the rubric instead of just showing them their weakness. The item that received the second largest percentage of disagreement (40\%) is Item 27 "Rubrics don't make any difference in my study. " It means that students may have made some difference in their study with the use of rubric in the classroom.

Item 20 is the one that received the most neutral answer, with $52 \%$. It can be inferred that half of the participants could not decide whether the teacher assess them in the traditional way - scoring, or use rubric to assess them. In short, the findings in this clusters were consistent with Powell's [18] and Scheneider's [19] studies. In other words, students have an overall positive perception toward the use of rubrics in their classroom. This can be resulted from the fact that students figured out the benefits of rubrics which will be discussed in details in the coming sections. 


\section{Students' perception toward the general benefits of analytic rubric for self-assessment}

Regarding students' perceptions toward the general benefits of analytic rubrics in self-assessment, most of the items (except Item 4 and 29) in the second cluster received positive feedback from the students (see Table 2). More specifically, $76.6 \%$ of the participants believe that the rubric made the evaluation fair and meaningful. In addition, $72.4 \%$ of students agreed that it was easier for them to comprehend teacher's grading if he or she evaluated the presentation basing on the rubrics. Moreover, $70.4 \%$ of participants agreed that rubrics helped them improve their oral presentation performance.

Other benefits that students claimed to receive from the implementation of analytic rubric could be found with Item 30, Item 34 and Item 28. In specific, more than sixty-five percent of students believe that they learn much more when they used rubrics in class. Rubrics with detailed criteria would help students to find out the standard to which they would try to follow. They would look for more information and learn more so as to reach the objective, therefore, they would enhance their learning. Moreover, students could compare their marks with their friends easily with the use of rubric, with $58.2 \%$ of agreement. Thanks to that, students claimed that they have been less surprised with their grade since they used the rubric.

Table 2 Students' perceptions towards the general benefit of analytic rubric in self-assessment

\begin{tabular}{|c|c|c|c|}
\hline Item & Agree (\%) & Disagree (\%) & No idea $(\%)$ \\
\hline Item 6: The rubrics made evaluation fair and meaningful. & 76.6 & 2 & 21.4 \\
\hline $\begin{array}{l}\text { Item 19: It is easier for me to understand my teacher's grading if he or she } \\
\text { would evaluate my presentation basing on the rubrics. }\end{array}$ & 72.4 & 3.1 & 24.5 \\
\hline Item 11: It improves my oral presentation performance. & 70.4 & 2 & 27.6 \\
\hline Item30: I learn much more if I use rubrics in class. & 65.3 & 5.1 & 29.6 \\
\hline $\begin{array}{l}\text { Item 34: Rubrics help me to compare my mark with that of other students } \\
\text { easily. }\end{array}$ & 58.2 & 8.1 & 33.7 \\
\hline Item 28: I am less surprised with my grade since I use the rubric & 54.1 & 8.1 & 37.9 \\
\hline $\begin{array}{l}\text { Item 4: I like the use of rubrics because it enables me to know what is expected } \\
\text { of me. }\end{array}$ & 46.9 & 8.2 & 44.9 \\
\hline Item 29 I have fewer questions about my assignment when I use rubric. & 35.7 & 20.4 & 43.9 \\
\hline
\end{tabular}

However, students disagreed most (43.9\%) with Item 29 which says "I have fewer questions about my assignment when I use rubric". In other words, students think they still have many questions to ask about their assignment when they use rubric. This could be because students were not very familiar with the use of rubric and thus, they had questions about applying to assess their performance.

In general, students' positive perceptions of students toward the use of rubric were consistent with what Stergar [20] found in his study. Therefore, EFL teachers may consider applying analytic rubric in their speaking classroom, especially when they want to evaluate students' oral presentation performance.

\section{Students' perception toward the benefits of analytic rubric in self-evaluating their preparation of oral presentation}

With regards to the benefits of analytic rubric in students' self-evaluating their preparation of oral presentation, it can be seen from Table 3 that the students are well-aware of the benefits that analytic rubric brings them in the process of preparing their oral presentation. Most noticeably, $86.6 \%$ of the participants consider the rubric as a tool to show them what the teacher wants them to do with the presentation. They can use the rubric to check their work beforehand and rubric can help them stick to the topic (Item 17 and Item 26, with $76.5 \%$ and $75.5 \%$ of agreement respectively).

Table 3 Students' perceptions towards the benefit of analytic rubric to students' preparation of a presentation

\begin{tabular}{|l|c|c|c|}
\hline \multicolumn{1}{|c|}{ Item } & Agree (\%) & Disagree (\%) & No idea (\%) \\
\hline Item 2: It shows me what the teacher wants me to do with the presentation. & 86.8 & 2 & 11.2 \\
\hline Item 1: The rubric helps me stick to the topic. & 76.5 & 4.1 & 19.4 \\
\hline Item 13: It enables me to understand the objective of the task. & 75.5 & 5.1 & 19.4 \\
\hline Item 17: I can check my oral preparation basing on the rubrics beforehand & 71.4 & 4.1 & 24.5 \\
\hline $\begin{array}{l}\text { Item 26: I feel easy to prepare my presentation because I use the rubric to } \\
\text { stick to my topic. }\end{array}$ & 62.3 & 9.1 & 28.6 \\
\hline
\end{tabular}

Furthermore, students agreed that they could check their preparation basing on the rubrics beforehand $(71.4 \%)$ and feel it easy to prepare their oral presentation $(62.3 \%)$.

In short, the results showed that most students have a positive attitude towards the use of Analytic Rubric for their preparation of a presentation. 
4. Students' perception toward the benefits of analytic rubric in evaluating their own oral presentation Table 4 revealed students' perception toward the benefits of analytic rubric in evaluating their own oral presentation.

One benefit of rubric is to provide detailed feedback, which are about students' strengths and weaknesses with $83.7 \%$ of agreement. More than three fourth of participants agreed with the facts that rubric enables them to assess themselves and makes it easier for evaluation (with $76.5 \%$ and $75.5 \%$ respectively).

For Item 25 "I still need my teacher's explanation after using the rubric.", $71.4 \%$ of the students agreed. These figures may indicate that the role of teacher's feedback is undeniable in the process of evaluating.

Table 4 Students' perceptions towards the benefit of analytic rubric to evaluate their own presentation

\begin{tabular}{|c|c|c|c|}
\hline Item & Agree (\%) & Disagree (\%) & No idea $(\%)$ \\
\hline Item 7: Rubrics give me detailed feedback of my strengths and weaknesses. & 83.7 & 5.1 & 11.2 \\
\hline Item 14: It enables me to assess myself. & 76.5 & 3.1 & 20.4 \\
\hline Item 15: The rubric makes it easier for evaluation. & 75.5 & 4.1 & 20.4 \\
\hline Item 25: I still need my teacher's explanation after using the rubric. & 71.4 & 9.2 & 19.4 \\
\hline Item 16: I can assess myself after I present my topic. & 70.4 & 6.1 & 23.5 \\
\hline $\begin{array}{l}\text { Item 22: I don't need any further explanations from my teacher after using the rubric to } \\
\text { assess myself. }\end{array}$ & 9.2 & 64.3 & 26.5 \\
\hline Item 32: If rubrics are used, there is no need for feedback from the teacher. & 9.2 & 78.6 & 12.2 \\
\hline
\end{tabular}

The two items that received the most disagreement from the participants are Item 32 and Item 22 . In other words, students did not think that rubrics can completely replace the role of teacher' feedback as well as their further explanations. In general, the results in this cluster showed that the students are well-aware of the benefits rubric brings them in the process of evaluating their own presentation but do not deny the roles of the teacher in helping them improve their oral performance via his or her feedback and explanations.

\section{Students' perceptions toward the difficulties of using analytic rubric for their speaking self-} assessment

The last cluster of the questionnaire reveals the students' perception towards the difficulties of using Analytic Rubric for their Speaking Self-Assessment. From Table 5, it can be seen that most of the students disagreed of the problems that they may face when using Rubric to self-assess.

Table 5 Students' perceptions towards the difficulties of using analytic rubric for their speaking self-assessment.

\begin{tabular}{|c|c|c|c|}
\hline Item & Agree (\%) & Disagree (\%) & $\begin{array}{l}\text { No idea } \\
(\%)\end{array}$ \\
\hline Item 31 Rubrics hinder my creativity. & 15.4 & 53 & 31.6 \\
\hline $\begin{array}{l}\text { Item } 5 \text { The rubric is too complicated for me to use because it has lots of } \\
\text { information. }\end{array}$ & 10.2 & 50 & 39.8 \\
\hline Item 12: I am afraid of making something new out of the rubrics. & 24.5 & 46.9 & 28.6 \\
\hline Item 24: I think the rubric is difficult for me because my level is too slow. & 58.2 & 9.1 & 32.7 \\
\hline
\end{tabular}

The results present that the students disagree with the problems while the research's hypothesis "The Students agreed to have encountered some problems when using Analytic Rubric for their Self-assessment in Speaking”. The results did not match the hypothesis. With careful observation of all the findings, it can be inferred that the students did not recognize the disadvantages of the use of Analytic Rubric. This means the students did not have clear perceptions towards the drawbacks of the use of Analytic Rubric.

\section{Conclusion}

The findings in the study imply that rubrics can be considered as a useful instructional and assessment tool. The findings strongly supported the hypothesis as well as the literature review. Through the findings and the results, it may be concluded that students positively perceive the benefits of the Analytic Rubric in both the process of preparation and evaluation of their own presentation. Moreover, the results also revealed the problems that students have encounter when using Analytic Rubric to self-assess.

Using Analytic Rubric to evaluate students' speaking performance is a new experience for the researcher and the students as well. The study was conducted to find out the students' perceptions towards this tool. The result would be useful for further research to find out more aspects of using Analytic Rubric, therefore, this tool should be applied appropriately in order to enhance students' learning progress. 


\section{References}

[1]. Nitko, A. J. (1996). Educational assessment of students, Second edition, Prentice-Hall Inc.

[2]. Reddy, Y. M., \& Andrade, H. (2010). A review of rubric use in higher

[3]. Wiggins, G. (1998). Educative Assessment. Designing Assessments To Inform and Improve Student Performance. Jossey-Bass Publishers, 350 Sansome Street, San Francisco, CA 94104.

[4]. Wiggins, Grant \& McTighe, Jay.(2005). Understanding by design. Alexandria, VA: Association for Supervision and Curriculum Development.

[5]. Linn, R.L., \& Gronlund, N.E. (2000). Measurement and assessment in teaching. Upper Saddle River, New Jersey: Prentice-Hall.

[6]. Boud, D. (2003). Enhancing learning through self assessment, RoutledgeFalmer.

[7]. Wiggins, G. (1991) Standards, Not Standardization: Evoking Quality Student Work. Educational Leadership48, 5, 18-25

[8]. Bolton, C.F. 2006. Rubrics and adult learners: Andragogy and assessment.Assessment Update 18, no. 3: 5-6.

[9]. Andrade, H., and Y. Du. 2005. Student perspectives on rubric-referenced assessment. Practical Assessment, Research \& Evaluation 10, no. 5: 1-11.

[10]. Powell, T.A. 2001. Improving assessment and evaluation methods in film and television production courses. PhD diss., Capella University. UMI No. 3034481

[11]. Schneider, J.F. 2006. Rubrics for teacher education in community college. The Community College Enterprise 12, no. 1: $39-55$.

[12]. Andrade, H. G. (2000). Using rubrics to promote thinking and learning. Educational leadership, 57(5), 13-19.

[13]. Osana, H. P., \& Seymour, J. R. (2004). Critical thinking in preservice teachers: A rubric for evaluating argumentation and statistical reasoning. Educational Research and Evaluation, 10(4-6), 473-498.

[14]. Tierney, R., \& Simon, M. (2004). What's still wrong with rubrics: focusing on the consistency of performance criteria across scale levels. Practical Assessment, Research \& Evaluation, 9(2), 1-10.

[15]. Song, K. H. (2006). A conceptual model of assessing teaching performance and intellectual development of teacher candidates: A pilot study in the US. Teaching in Higher Education, 11(2), 175-190.

[16]. Haugnes, N., \& Russell, J. L. (2016). Don't Box Me In: Rubrics for Àrtists and Designers. To Improve the Academy, 35(2), 249283.

[17]. Gliem, J. A., \& Gliem, R. R. (2003). Calculating, interpreting, and reporting Cronbach's alpha reliability coefficient for Likert-type scales. Midwest Research-to-Practice Conference in Adult, Continuing, and Community Education.

[18]. Powell, T. A. (2001). Improving assessment and evaluation methods in film and television production courses. PhD diss., Capella University. UMI, (3034481).

[19]. Schneider, J.F. 2006. Rubrics for teacher education in community college. The Community College Enterprise 12, no. 1: $39-55$.

[20]. Stergar, C. (2005). Performance tasks, checklists, and rubrics. Glenview: Pearson Education. 